\title{
The Impact of Matrix Treatment (Family Training) in Reducing the Amount of Drug Consumption in Heroin and Crack Addicts
}

\author{
Seyyed Hossein Seid, Narges Dolatyari* \\ Department of Clinical Psychology, College of Psychology, Science and Research Branch, Islamic Azad \\ University, Alborz, Iran \\ Email: ${ }^{*}$ N.dolatyarii@gmail.com
}

Received 17 December 2014; accepted 25 March 2015; published 1 April 2015

Copyright (C) 2015 by authors and Scientific Research Publishing Inc.

This work is licensed under the Creative Commons Attribution International License (CC BY).

http://creativecommons.org/licenses/by/4.0/

(c) (i) Open Access

\begin{abstract}
The purpose of this study is to investigate the impact of family training based on matrix model in reducing the amount of drug consumption by heroin and crack addicts. The subjects were referral to Karaj Clinic, Karaj City, Iran, for crack abuse in 2013. In order to select participants convenience sampling was been used and totally 45 patients were selected (15 heroin addict, 15 crack addict, and 15 with combination of heroin and crack addiction) and put into two groups of experimental and control groups randomly. For collecting the data, Addiction Severity Index questionnaire was used. Descriptive and inferential statistics were used through one-way analysis of covariance for data analyzing. The results indicated that there was statistical difference between the experimental and control group with consumption of heroin and crack in family status, mental and substance use and also it has been shown that the experimental group with heroine consumption achieved better performance compared with the control group in the amount of consumption.
\end{abstract}

\section{Keywords}

Matrix Treatment (Family Training), Drug Consumption, Heroin, Crack

\section{Introduction}

Addiction is one of the four top crises of the $21^{\text {st }}$ century and one of the major problems in health, psychosocial, and social fields as well as the most important cause of unsafe behaviors in society. Drug abuse, dependence, and addiction are complex disorders that are outcomes of causes and effects of biological, psychological, social

"Corresponding author.

How to cite this paper: Seid, S.H. and Dolatyari, N. (2015) The Impact of Matrix Treatment (Family Training) in Reducing the Amount of Drug Consumption in Heroin and Crack Addicts. Health, 7, 419-422.

http://dx.doi.org/10.4236/health.2015.74048 
and spiritual reasons. Heroin is used in Iran as a drug. According to Diagnostic and statistical manual disorders 4th edition (DSM-IV-TR) [1], the rate of prevalence of heroin use is about $1 \%$ in lifetime and $20 \%$ of people have been used it over a year ago. The ratio of addiction to heroin by men and women is 3 to 1 . Heroin addicts usually start taking in the third decade of their life.

Crack, which is sometimes also called rack is a stimulant substance that is obtained from refining cocaine and it is used in various forms of smoking (inhaling smoke). Crack, despite opium or heroin, is odorless substance; it is easy to use and it can be used anywhere by a lighter.

"Matrix" is the name of the first specific treatment for amphetamine abuse and it is originated for the Western countries. This method includes group therapy sessions for patients and family and group psychotherapy sessions for family members, and other interventions and skills training necessary for avoiding this substance [2]. Between 1994 and 1999, statistics in the United States indicated 37\% growth of drug dependence or abuse [3]. It has been estimated that about 4.6 million people in the United States suffer from substance abuse disorders and mental disorders [4].

In the study by Choi and Ryan [4] to determine the relationship between drug abuse of mother and children's welfare, it was found that approximately $1.3 \%$ of the children had been neglected by their mother. Approximately, 4\% of children suffered from physical abuse and 5\% had experienced sexual abuse. Among 602 children who lived away from home, only $12 \%$ returned to home one year later [4].

\section{Methodology}

The researchers used a quasi-experimental method with pre-test - post-test and a control group. Therefore, 30 patients who were suffering from crack addiction in Karaj City were selected after checking their age, and lack of personality disorder. These patients, then attended a brief session to discuss ethics and the matrix (family training) therapy.

\subsection{Participants}

In order to select a case group convenient sampling was used and totally, from all patients with heroin and crack who referred to Karaj Clinic, 45 patients were selected (15 patients with heroin, 15 patients with crack, and 15 patients with a combination of heroin and crack addiction) and put in two groups of experimental and control groups randomly.

\subsection{Instrument}

Addiction Severity Index: In order to evaluate the clinical status of patients, Addiction Severity Index, Fifth Edition [5] was used. It is a semi-structured interview that needs to be implemented by trained researchers through face to face interaction with patients. This questionnaire collects the patients' problems in each area during the last 30 days, last year and their lifetime. This scale contains 116 questions. Eight questions are about a medical condition, 27 questions are about the job situation, 24 questions are on the status of drugs and alcohol consumption, 27 questions are on legal status, family status, and 13 of questions are about the patient's mental status. Evaluating the reliability and validity of the Persian version used in this study was done by Atef et al., Department of Tehran University, in cooperation with the National Center for Addiction Studies and budget of the Center for Combating Drugs [6]. Pretest was administered after forming the groups on their parent. Parents and parents with first and second drug are assigned to experimental groups. At the same time, all three groups of participants were treated by used methadone therapy. After the training matrix (family training) on the parents of both groups, post test was administered on three groups. Finally, the performance of parent in both groups tested on each of the three groups of parents with narcotics and stimulants substance compared to the control group and with each other. Then the data was analyzed by SPSS software.

\section{Results}

In order to analyze the data, descriptive and inferential statistics were used through one-way analysis of covariance. In Table 1, the mean and standard deviation of consumption in the pre-test and post-test and control groups are presented.

As listed in Table 1 the findings indicate a decrease in mean of Addiction Severity scales in experimental 
group comparing with the control group on indicators of family status, mental status, and narcotic substance use. According to some of these dependent variables and testing this variable and pre-test and post-tests of multiple covariance (MANCOVA) was used. Therefore, independent variables were in the crack experimental and control groups and pre-test sizes of indicators were covariate variables (medical status, job status, legal status, family status, mental status, and substance use) and post-test sizes of indicators (medical status, job status, legal status, family status, mental status, and substance use) were dependent variables. Bartlett's test was used in order to investigate the correlation between the size of the dependent variables.

Results of multivariate analysis of covariance revealed significant differences between the experimental group with heroin and experimental group with crack that both groups have received matrix training regarding various indices of drug use. Since only effect of experimental group with heroin and experimental group with crack is significant, therefore, variance analysis was used in order to study their difference performance in dependent sizes of drug consumption variable.

As can be seen in Table 2, despite the differences between the experimental group with heroin and experimental group with crack, analysis of the differences between experimental and control groups show significant difference in family status, mental status, and substance use ( $p<0.05)$. So, it can be say that matrix treatment (family training) improved that experimental group with heroin's performance in family status, mental health and substance use with experimental group with crack. This indicates the robustness of treat crack to psychological interventions. Lower mean of group with heroin in posttest with different indices of drug use are illustrated in Table 2.

\section{Discussion}

The results showed that the effect of the matrix treatment (family training) in reducing the amount of heroin addicts and crack addicts is not equal and the method had the greatest effect on heroin addicts. It seems that the first reason for this result is the nature of the crack that had deeper and more lasting impact on people. Some of the symptoms of crack addiction include prominent changes in personality and behavior, loss of focus, loss of weight, invisible of expensive objects in home and the lack of a convincing explanation for the amount of money spent, traveling with addicts, considerable confusion, vindictive behavior with family and friends, irregular sleep, neglecting the external beautification Severe paranoia (suspicion to all), restlessness and an early sign of

Table 1. The results of multiple covariance test about experimental and control groups in the amount of crack use.

\begin{tabular}{ccccc}
\hline $\mathrm{F}$ & Error df & Assumed df & Amount & Tests \\
\hline $2.21^{*}$ & 82 & 4 & 0.61 & Fyla track Group \\
$2.21^{*}$ & 82 & 4 & 0.29 & Wilks' lambda \\
$2.21^{*}$ & 82 & 4 & 1.01 & Hatlyng T track \\
$2.21^{*}$ & 82 & 4 & 1.48 & Largest epilhizous \\
\hline
\end{tabular}

$\mathrm{p}<0.05^{*}$.

Table 2. The results of variance analysis test for the effect of groups and interaction in the amount of crack and heroine consumption.

\begin{tabular}{|c|c|c|c|c|c|c|}
\hline Size of effect & Sig & $\mathrm{F}$ & Mean square & $\mathrm{df}$ & Collected square & $\begin{array}{c}\text { Dependent } \\
\text { variable }\end{array}$ \\
\hline 0.09 & 0.26 & 0.35 & 0.09 & 1 & 0.09 & Medical status \\
\hline 0.01 & 0.92 & 0.11 & 0.08 & 1 & 0.08 & Job status \\
\hline 0.03 & 0.96 & 0.22 & 0.18 & 1 & 0.18 & Salary status \\
\hline 0.35 & 0.03 & 5.19 & 0.2 & 1 & 0.2 & Family status \\
\hline 0.32 & 0.02 & 23.5 & 0.28 & 1 & 0.28 & Mental status \\
\hline 0.31 & 0.01 & 59.01 & 0.19 & 1 & 0.19 & Substance use \\
\hline
\end{tabular}


crack abuse, abrupt separation of physical/spiritual person from family circle and his dramatic behavior change [7]. This is in line with findings from research by [2] [8]-[10]. Future studies can focus follow-up phase at least 4 months after treatment.

\section{Conclusion}

Given that the families can be effective in reducing the amount of consumption in people who abuse substances, future research can be investigated about the involvement of parents.

\section{References}

[1] American Psychiatric Association (2000) Diagnostic and Statistical Manual of Mental Disorders. Fourth Edition, (Translated by Mohammad Reza Nikhkoo and Avadis Yans, 2002). Tehran: Speech.

[2] Rawson, R.A., Obert, J.L., McCann, M.J., Smith, D.P. and Ling, W. (1990) Neurobehavioral Treatment for Cocaine Dependency. Journal of Psychoactive Drugs, 22, 159-171. http://dx.doi.org/10.1080/02791072.1990.10472541

[3] Sarrami, R. (2001) Various Drugs and Industrial Chemicals. Parshokooh, Tehran.

[4] Choi, S. and Ryan, J. (2007) Co-Occurring Problems for Substance Abusing Mothers in Child Welfare: Matching Services to Improve Family Reunification. Children and Youth Services Review, 29, 1393-1410. http://dx.doi.org/10.1016/j.childyouth.2007.05.013

[5] McLellan, T., et al. (2001) Does Clinical Case Management Improve Outpatient Addiction Treatment. Journal of Drug and Alcohol Dependence, 55, 99-103.

[6] Minooie, M. and Salehi, M. (2002) Evaluating the Feasibility, Reliability, Validity and Standardization of Tests MAC-R, AAS, APS to Identify Individuals at Risk and Prone to Substance Abuse among High School Students in Tehran. Journal of Substance Abuse, The First Year of the Third Number.

[7] Zkikariaie, M.A. (2002) Addiction Research. Journal of Substance Abuse. Second Year. Spring. No. 6.

[8] Kalduie, A. (2011) Comparative Efficacy of Mindfulness-Based Matrix and Prevent the Return of the Combined Approach in Preventing the Return of People Referring to Addiction Zahedan, Unpublished Ph.D. Dissertation, Allameh Tabatabai University, Tehran.

[9] Shoptaw, S., Frosch, D., Rawson, R. and Ling, W. (1997) Cocaine Abuse Counseling as HIV Prevention. Journal of AIDS Education \& Prevention, 9, 511-520.

[10] Roll, J.M., Rawson, R.A., Ling, W. and Shoptaw, S., Eds. (2009) Methamphetamine Addiction: From Basic Science to Treatment. Guilford Press, New York. 